\title{
Non-Neoplastic Bladder Disorder
}

National Cancer Institute

\section{Source}

National Cancer Institute. Non-Neoplastic Bladder Disorder. NCI Thesaurus. Code C27601.

A non-neoplastic disorder that affects the urinary bladder. Representative examples include cystitis, cystolithiasis, and urinary bladder rupture. 